\title{
Bagaimanakah Peran MKEK dalam Menyikapi Macetnya Eksekusi Keputusan Sidang MKEK yang Melibatkan Otoritas Lain?
}

\author{
Pukovisa Prawiroharjo ${ }^{\mathrm{I}, 2^{*}}$, Prijo Sidipratomo ${ }^{\mathrm{I}, 3^{*}}$, Yuli Budiningsih ${ }^{\mathrm{I}, 4}$ \\ ${ }^{\mathrm{I}}$ Majelis Kehormatan Etik Kedokteran Pengurus Besar Ikatan Dokter Indonesia \\ ${ }^{3}$ Departemen Neurologi, Fakultas Kedokteran Universitas Indonesia/Rumah Sakit Cipto Mangunkusumo, Jakarta \\ ${ }^{3}$ Fakultas Kedokteran Universitas Pembangunan Nasional Veteran Jakarta \\ ${ }^{4}$ Departemen Ilmu Kedokteran Forensik dan Medikolegal, Fakultas Kedokteran Universitas Indonesia/Rumah Sakit Cipto Mangunkusumo \\ * Penulis-penulis ini berkontribusi seimbang (Theseauthars contributed equally)
}

\author{
Kata Kunci \\ Korespondensi \\ pukovisa@ui.ac.id \\ Publikasi \\ (C) 20I8 JEKI/ilmiah.id \\ DOI \\ I0.26880/jeki.v2i3.23
}

eksekusi macet, MKEK, sanksi

Tanggal masuk: 8 Juli 2018

Tanggal ditelaah: II Oktober 2018

Tanggal diterima: I9 Oktober 2018

Tanggal publikasi: 24 Oktober 2018
Abstrak Dalam tugasnya untuk menegakkan nilai-nilai luhur profesi kedokteran, selama 68 tahun ini seluruh keputusan yang dihasilkan Majelis Kehormatan Etik Kedokteran Ikatan Dokter Indonesia (MKEK IDI) dapat dilaksanakan dengan baik. Akibatnya, tidak ada redaksi yang antisipatif atau memprediksi akan ada batu sandungan dalam eksekusi putusan MKEK sampai pada perubahan terakhir Pedoman Organisasi dan Tatalaksana Kerja (Ortala) MKEK di tahun 2008. Namun akhirnya kini muncul satu kasus yang eksekusinya macet dan tanpa kejelasan. Oleh karena itu, dalam upaya pembaharuan Ortala saat ini harus dituangkan dengan tegas apa yang dapat dilakukan MKEK bila eksekusi putusannya macet. Saat ini ada dua hal yang dapat dilakukan, yaitu peran Ketua MKEK aktif mengingatkan dan meminta rapat Majelis Pimpinan Pusat (MPP) IDI, serta melakukan klarifikasi dan penelaahan proaktif jika terdapat informasi adanya penyumbatan eksekusi putusan MKEK. Artikel ini merekomendasikan perubahan Ortala MKEK untuk mengatasi kebuntuan eksekusi putusan etik lebih lanjut, melalui pembagian porsi kewenangan eksekusi kepada MKEK dan adanya opsi pengambilalihan kewenangan eksekusi oleh MKEK pada proses eksekusi yang mengalami kebuntuan.

Abstract In its duty to uphold the honorable values of the medical profession, all decisions of Medical Ethics Council of Honor of Indonesian Medical Association (MKEK IDI) have been implemented accordingly in these 68 years. As a result, there is no anticipation nor prediction for any obstacle in the execution of MKEK verdicts until the last revision of MKEK Organization and Management Guidelines (Ortala) in 2008. But then a case emerged with such obstacle and no clarity. Therefore, in the ongoing revision of Ortala it must be clearly stated what MKEK can do when such obstacle occurs. At present there are two things that can be done, namely the role of MKEK Chairperson to actively remind and request meetings of the Central Executive Board, as well as making clarification and proactive investigation if there is any information about such obstacles. In order to overcome the deadlock of its verdict execution, this article recommended Ortala revision so that MKEK shares some portion of execution rights and has option to take over a deadlocked execution. 


\section{PENDAHULUAN}

Sejarah profesi dokter tidak dapat lepas dari nilai-nilai luhur etika kedokteran, yang menjadikan profesi ini demikian dihormati dan mendapat tempat yang spesial di kalangan masyarakat. Demikian pula nilai-nilai luhur tersebut tidak dapat lepas dari keberadaan Majelis Kehormatan Etik Kedokteran (MKEK), yang selama ini bertugas untuk menjunjung dan menegakkan prinsip-prinsip etik profesi, melalui berbagai sanksi yang bertujuan membina dan bukan menghukum, membangun profesi dari dalam untuk menjadi pribadi yang semakin

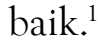

Salah satu opsi sanksi paling berat yang dapat dihasilkan sidang kemahkamahan MKEK menurut Pedoman Organisasi dan Tatalaksana Kerja (Ortala) MKEK tahun 2008, yang hanya diberikan pada pelanggaran etik amat berat, adalah pemecatan keanggotaan sementara hingga tetap. ${ }^{2}$ Sanksi ini membutuhkan keterlibatan otoritas internal organisasi profesi maupun eksternal pada sistem birokrasi negara. Pada internal organisasi profesi, otoritas itu dimiliki eksekutif Ikatan Dokter Indonesia (IDI) mulai dari tingkat Pengurus Besar (PB IDI), IDI Wilayah, IDI Cabang, serta Perhimpunan Dokter Spesialis/Pelayanan Primer (PDSp/ PDPP). Organisasi eksekutif IDI tersebut kemudian akan mencabut rekomendasi, dan oleh karena rekomendasi organisasi profesi menjadi syarat dan ketentuan sah dan berlakunya Surat Izin Praktek (SIP), Surat Tanda Registrasi (STR), dan administrasi lain yang terkait, maka seluruh administrasi tersebut menjadi tidak sah dalam kurun waktu yang ditetapkan pada Surat Keputusan MKEK. Sementara pada eksternal organisasi profesi, berbagai lembaga birokrasi negara memiliki otoritas masing-masing agar sanksi yang ditetapkan MKEK tersebut menjadi efektif dapat dikerjakan.

Dalam sejarah panjang IDI dan MKEK IDI yang telah berusia 68 tahun, selama ini keputusan MKEK selalu dapat ditegakkan dan dilaksanakan dengan baik. MKEK dipandang sebagai mahkamah yang terhormat baik di internal maupun eksternal organisasi. Demikian pula segenap organisasi eksekutif
IDI dan seluruh jajaran birokrasi negara juga memelihara kehormatan dirinya dengan selalu mengeksekusi putusan MKEK secara tuntas dan tanpa hambatan. Akibatnya, tidak ada redaksi yang antisipatif atau memprediksi akan ada batu sandungan dalam eksekusi putusan MKEK sampai pada perubahan terakhir Ortala MKEK di tahun 2008. Barulah saat IDI merayakan ulang tahunnya yang ke-68, terdapat satu kasus yang eksekusinya macet dan tanpa kejelasan.

Artikel ini ditulis tidak untuk membahas kasus tersebut, namun adanya preseden perdana ini memerlukan suatu penarasian khusus dalam draf perubahan Ortala MKEK yang sedang disusun mengenai apa yang dapat diusahakan MKEK jika mengalami situasi seperti ini. Artikel ini mencoba menjawab pertanyaan di atas, bagaimanakah peran MKEK dalam menyikapi macetnya eksekusi keputusan sidang MKEK yang melibatkan otoritas lain?

Saat ini dengan keterbatasan Ortala yang kurang antisipatif terhadap peluang macetnya eksekusi putusan MKEK, langkah yang dapat dilakukan oleh MKEK untuk menyikapi hal tersebut di antaranya sebagai berikut:

1. Peran Ketua MKEK dan MKEK Pusat untuk mengingatkan secara aktif otoritas sumber kemacetan eksekusi.

Sebenarnya dengan MKEK telah melaksanakan yurisdiksinya membuat keputusan melalui tata cara persidangan yang benar, maka sejatinya tiang keadilan dan kebenaran demi tegaknya marwah profesi kedokteran telah dipancangkan. Tiang itu tidak bergeser, tumbang, maupun lapuk dengan belum atau tidak dieksekusinya putusan tersebut oleh otoritas lain. Pelaksanaan yurisdiksi yang baik mencerminkan bahwa MKEK telah tuntas dalam pertanggungjawaban moralnya kepada seluruh insan profesi kedokteran dan kesehatan serta masyarakat Indonesia. Keseluruhan proses ini adalah domain MKEK, sementara eksekusi yang membutuhkan otoritas lain bukan lagi menjadi beban amanah MKEK.

Namun demikian, untuk menunjukkan bahwa MKEK setia dalam nilai keadilan dan kebenaran, maka Ketua MKEK/Ketua Dewan Etik PDSp/PDPP yang membuat keputusan bersama dengan Ketua MKEK 
Pusat perlu mengingatkan segenap otoritas sumber kemacetan eksekusi tersebut. Upaya administrasi maksimal sejauh yang masih dalam rentang yang diatur dalam Ortala MKEK 2008 adalah MKEK dapat mengirimkan informasi dan putusan kepada Ketua PB IDI, MKEK Wilayah, MKEK Cabang, dan PDSp/PDPP terkait. $^{2}$ Sementara itu, upaya pengingatan sepanjang sesuai aturan AD/ART IDI 2015 dapat dilakukan dengan menghubungi mereka secara aktif, meminta hal ini diputuskan dalam rapat Majelis Pimpinan Pusat (MPP) IDI dan menindaklanjuti progresivitas keputusan dalam rapat MPP tersebut. ${ }^{3}$ Upaya pengingatan ini perlu dijelaskan dalam draf perubahan Ortala untuk memperjelas kewenangan Ketua MKEK/ Ketua Dewan Etik PDSp/PDPP bersama dengan Ketua MKEK Pusat tersebut.

2. Memperjuangkan Tata Aturan Internal IDI yang lebih mengedepankan supremasi penegakan etik.

Sejauh ini hanya mekanisme pengingatan dan permintaan rapat MPP saja yang dapat diupayakan MKEK sebagai suatu organ sesuai dengan tata aturan yang ada di internal IDI. Diharapkan suatu saat IDI dapat mengadopsi tata kelola yang lebih mengedepankan supremasi penegakan etik dan memungkinkan memberikan sanksi serius kepada oknum dan pihak yang melakukan obstruksi/penyumbatan supremasi penegakan etika kedokteran ini dengan sebaik-baiknya. Sebagai perbandingan adalah konstitusi Republik Indonesia sendiri, yang menyatakan bahwa negara kita menjunjung tinggi supremasi hukum dengan pernyataan "Negara Indonesia adalah negara hukum" (UUD 1945 Amandemen IV pasal 1 ayat 3). ${ }^{4}$ Dalam konstruksi negara hukum kita, seluruh putusan pengadilan dilaksanakan oleh jaksa, panitera, atau juru sita (UU Nomor 48 Tahun 2009 tentang Kekuasaan Kehakiman, pasal 54) dan tidak dapat diganggu gugat apalagi dihalanghalangi oleh siapapun (pasal 3 ayat 2-3). ${ }^{5}$ Pejabat yang ditugaskan pun terikat pada kewajibannya dan harus melaksanakannya dalam 45 hari, atau ia berisiko untuk diberhentikan secara tidak hormat dari pekerjaannya (UU Nomor 16 tahun 2004 tentang Kejaksaan RI, pasal 13 ayat $1 \mathrm{~b}$ dan penjelasannya). ${ }^{6}$
Jika suatu saat IDI telah mengadopsi tata kelola yang lebih mengedepankan penegakkan keadilan, seperti misalnya memungkinkan dilakukan sanksi internal kepada pejabat eksekutor yang tidak melaksanakan kewajibannya dalam 45 hari, maka Ketua MKEK dapat mencermati bagaimana tata kelola ini dapat diselenggarakan.

3. Melakukan Klarifikasi dan Penelaahan Proaktif jika Terdapat Informasi Adanya Oknum yang Diduga Berperan Aktif Melakukan Obstruksi/

Penyumbatan Penegakkan Supremasi Etik

Salah satu pembahasan yang digulirkan dalam wacana perubahan draf Ortala MKEK ialah penguatan peran Divisi Pembinaan. Dalam Ortala 2008, Divisi Pembinaan dapat mencari temuan terhadap suatu informasi tentang dugaan pelanggaran etik. Semangat kinerja ini dapat diperkuat dengan eksplisit menyebutkan proaktif untuk melakukan klarifikasi, penelaahan, dan jika disetujui juga menyelenggarakan sidang pembinaan terhadap suatu informasi tentang dugaan pelanggaran etik. $^{7}$ Tentu seluruh rangkaian klarifikasi dan penelaahan yang diselenggarakan harus menjaga prinsip praduga tak bersalah. Untuk menjaga netralitas dan motivasi berlebih, maka dapat diatur dalam Ortala MKEK bahwa sidang pembinaan tersebut agar tidak dihadiri oleh seluruh anggota Majelis Pemeriksa yang menangani dan memutuskan perkara terkait. Hasil klarifikasi dan penelaahan kemudian dapat diproses sesuai dengan aturan yang berlaku.

\section{HASIL DAN PEMBAHASAN}

\section{Perubahan Ortala MKEK sebagai solusi kebuntuan eksekusi putusan MKEK}

Beberapa rekomendasi Ortala MKEK yang diajukan sebagai alternatif solusi terhadap kebuntuan eksekusi putusan MKEK adalah:

1. Seluruh pelanggaran etik diberi minimal satu jenis sanksi pembinaan perilaku yang eksekusinya menjadi wewenang Divisi Pembinaan MKEK

Wacana perubahan Ortala MKEK sedang disusun mengenai pembagian sanksi etik menjadi tiga kategori: kategori 1 (pembinaan perilaku), kategori 2 (penginsafan tanpa 
pemecatan), dan kategori 3 (penginsafan dengan pemecatan sementara), di mana masingmasing diterapkan pada pelanggaran etik ringan, sedang, dan berat secara akumulatif. ${ }^{8}$ Bila wacana ini disepakati maka sanksi berupa pemecatan keanggotaan akan digolongkan dalam sanksi kategori 3, dan penetapan sanksi ini tidak dapat berdiri sendiri melainkan harus juga disertai minimal satu jenis sanksi kategori 2 dan minimal satu jenis sanksi kategori 1 . Sementara perkara yang diputus melanggar etik sedang akan menerima minimal satu jenis sanksi kategori 2 dan satu jenis sanksi kategori 1. Dan yang diputus melanggar etik ringan akan menerima minimal satu jenis sanksi kategori $1 .^{3}$

Dalam eksekusinya, kategorisasi sanksi yang baru seperti uraian di atas masih memerlukan otoritas internal maupun eksternal organisasi profesi. Bedanya ialah kewenangan eksekusi sanksi kategori 1 - yang mana akan diberikan kepada semua pelanggar etik baik ringan, sedang, dan berat - akan menjadi tanggung jawab penuh Divisi Pembinaan MKEK. Jika skema ini disetujui, maka setidaknya MKEK memiliki sebagian akses dan peran dalam mengeksekusi hampir seluruh putusannya.

2. Pengambilalihan wewenang eksekusi sanksi kategori 2 dan 3 oleh MKEK jika otoritas kepengurusan IDI dan seluruh organisasi di bawahnya tidak mengeksekusi putusan MKEK tersebut.

Fiat Justitia ruat caelum, fiat Justitia et pereat mundus. Keadilan harus ditegakkan meskipun langit runtuh, meskipun dunia harus binasa. Jika keadilan telah tercermin dalam putusan MKEK, maka supaya keadilan benar-benar ditegakkan, mekanisme eksekusi harus dibuat serba pasti agar menghadirkan kepastian etik (rechssicherheit).

Dalam konstruksi hukum negara, memang tidak dijumpai keadaan di mana pengadilan mengambil alih wewenang kejaksaan dalam eksekusi putusan pidana yang buntu akibat ketidakprofesionalan jaksa yang dimandatkan. Yang ada ialah jaksa tersebut diberhentikan dengan tidak hormat dengan tenggat waktu 45 hari sejak putusan dibuat. ${ }^{7}$ Namun dalam tata aturan rumah tangga IDI yang ada saat ini, hal tersebut tidak diatur. Akan menjadi kisruh debat yang tak perlu di dalam organisasi profesi jika sampai pejabat puncak eksekutif IDI dicopot karena tidak mengeksekusi putusan MKEK. Lain halnya jika IDI menunjuk badan khusus untuk mengeksekusi setiap putusan MKEK, sehingga pemberhentian tidak hormat seperti dalam analogi pengadilan dan jaksa di atas tidak diberlakukan untuk pimpinan puncak IDI secara langsung, tetapi untuk sejawat penanggung jawab eksekusi putusan tersebut.

Di sisi lain, aktivitas seorang dokter di IDI bukanlah suatu hubungan pekerjaan. Seorang Ketua IDI tidak menerima gaji maupun tunjangan apapun dari IDI, demikian pula Ketua MKEK. Oleh karenanya, sampai pada pemberhentian tidak hormat seperti diuraikan di atas nampaknya berlebihan untuk diberlakukan dalam konstruksi IDI. Namun di sisi lain, upaya terus menegakkan marwah etik profesi kedokteran tetap harus menjadi prioritas untuk dilakukan dengan penuh kesungguhan. Oleh karena itu ppsi jalan tengah yang diajukan ialah tetap memberikan wewenang eksekusi pada organ eksekutif IDI dan seluruh organisasi di bawahnya tetapi jika wewenang ini tidak ditunaikan dengan baik, maka alihalih diberlakukan mekanisme sanksi kepada organ eksekutif IDI, penyelesaiannya adalah kewenangan tersebut diambil alih oleh MKEK untuk mengeksekusi putusan yang dihasilkan dengan sempurna. Divisi Kemahkamahan MKEK dan Ketua MKEK dapat diberikan tanggung jawab untuk melakukan hal ini dengan sempurna.

\section{KESIMPULAN}

Terdapat dua hal yang saat ini dapat dilakukan oleh MKEK jika menemui macetnya eksekusi putusan MKEK, yaitu peran Ketua MKEK aktif mengingatkan dan meminta rapat MPP, serta melakukan klarifikasi dan penelaahan proaktif jika terdapat informasi adanya oknum yang diduga berperan aktif melakukan penyumbatan eksekusi putusan MKEK. Dua hal ini perlu dinyatakan secara jelas pada draf perubahan Ortala MKEK sehingga mengisi kekosongan aturan yang selama ini tidak diantisipasi di Ortala MKEK 
sebelumnya, terutama karena memang selama ini eksekusi putusan MKEK selalu dijalankan secara baik. Jika dalam perubahan aturan IDI mendatang MKEK diberi peran lebih luas dalam memperjuangkan eksekusi putusannya, maka MKEK secara moral wajib memperjuangkan sesuai koridor peran yang diberikan.

\section{KONFLIK KEPENTINGAN}

Tidak ada konflik kepentingan.

\section{REFERENSI}

1. Rozaliyani A, Meilia PDI, Librianty N. Prinsip penetapan sanksi bagi pelanggaran etik kedokteran. J Etik Ked Ind. 2018 Mar 19;2(1):19. https://doi.org/10.26880/jeki.v2i1.11.

2. Purwadianto A, editor. Pedoman organisasi dan tata laksana kerja Majelis Kehormatan Etik Kedokteran. Jakarta: Majelis Kehormatan Etika Kedokteran Ikatan Dokter Indonesia; 2008.

3. Muktamar Ikatan Dokter Indonesia XXIX. Anggaran dasar dan anggaran rumah tangga Ikatan Dokter Indonesia. 2015.

4. Undang-Undang Dasar Negara Republik Indonesia Tahun 1945 Amandemen IV. 2002.

5. Undang-Undang Republik Indonesia nomor 48 tahun 2009 tentang kekuasaan kehakiman. 2004.

6. Undang-Undang Republik Indonesia nomor 16 tahun 2004 tentang Kejaksaan Republik Indonesia. 2004.

7. Santosa F, Prawiroharjo P. Pemberdayaan divisi pembinaan MKEK melalui kerja proaktif dan pemberian sanksi berupa pembinaan. Belum diterbitkan.

8. Prawiroharjo P, Purwadianto A. Sistem akumulasi sanksi: Usulan perubahan kategorisasi dan akumulasi penetapan sanksi untuk pelanggaran etik kedokteran. Belum diterbitkan. 

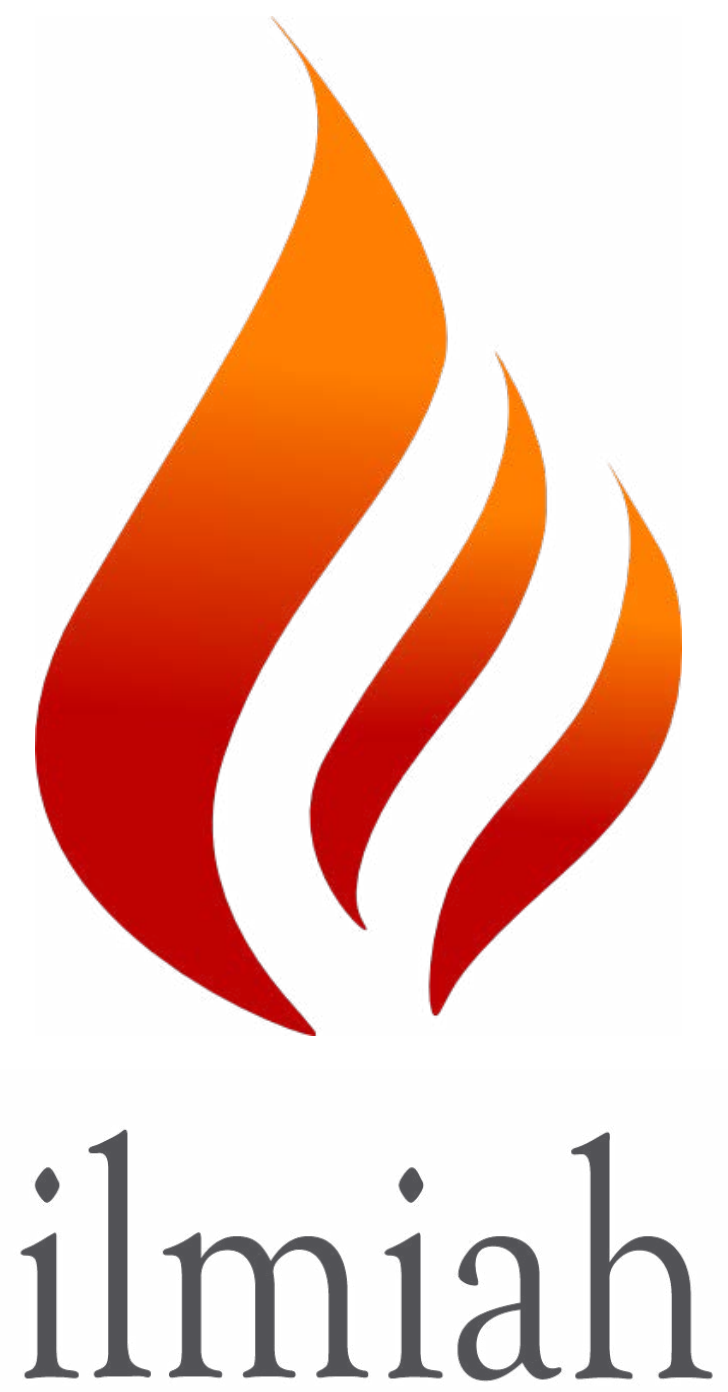

http://www.ilmiah.id your journal portal 